\title{
Quantum-Chemical ab initio Calculations on the Three Isomers of Diborabenzene $\left(\mathrm{C}_{4} \mathrm{H}_{4} \mathrm{~B}_{2}\right)$
}

\author{
Jaswinder Singh $^{\mathrm{a}}$, Yuekui Wang ${ }^{\mathrm{b}}$, and Gerhard Raabe \\ ${ }^{a}$ Institut für Organische Chemie, RWTH Aachen University, Landoltweg 1, D-52074 Aachen, \\ Germany \\ ${ }^{b}$ Key Laboratory of Chemical Biology and Molecular Engineering of the Education Ministery, \\ Institute of Molecular Science, Shanxi University, Taiyuan, Shanxi 030006, P. R. China
}

Reprint requests to G. R..; Fax: +49 24180 92385; E-mail: gerd.raabe@ thc.rwth-aachen.de

Z. Naturforsch. 65a, 113 - 122 (2010); received June 12, 2009

Dedicated to Professor Dr. Jörg Fleischhauer on the occasion of his $70^{\text {th }}$ birthday

\begin{abstract}
Quantum-chemical ab initio calculations up to the ZPE+CCSD(T)/aug-cc-pVTZ//MP2/6$311++\mathrm{G}^{* *}$ level were performed on three possible structural isomers of diborabenzene $\left(\mathrm{C}_{4} \mathrm{H}_{4} \mathrm{~B}_{2}\right)$. All three molecules were found to be local minima on the $\mathrm{C}_{4} \mathrm{H}_{4} \mathrm{~B}_{2}$ energy surface and to have closed shell singlet ground states. While the ground states of the 1,3- and 1,4-isomer are planar and of $C_{2 \mathrm{v}}$ and $D_{2 \mathrm{~h}}$ symmetry, respectively, 1,2-diborabenzene is non-planar with a $C_{2}$ axis passing through the center of the BB bond and the middle of the opposite carbon-carbon bond as the only symmetry element. The energetically most favourable 1,3 -diborabenzene was found to be about 19 and $36 \mathrm{kcal} / \mathrm{mol}$ lower in energy than the 1,2- and the 1,4-isomer. Planar 1,3- and 1,4-diborabenzene have three doubly occupied $\pi$ orbitals while non-planar 1,2-diborabenzene has also three doubly occupied orbitals which can be derived from the $\pi$ orbitals of its $3.7 \mathrm{kcal} / \mathrm{mol}$ energetically less favourable planar form (" $\pi$-like" orbitals). The lowest unoccupied orbitals of all three isomers have $\sigma$ symmetry with large coefficients at the two boron atoms. These orbitals are lower in energy than the lowest unoccupied molecular orbitals (LUMOs) of e.g. benzene and pyridine and might cause pronounced acceptor properties which could be one of the reasons for the elusiveness of the title compounds. The results of bond separation reactions show that cyclic conjugation stabilizes all three diborabenzenes relative to their isolated fragments. The most effective stabilization energy of about $24 \mathrm{kcal} / \mathrm{mol}$ was found for the energetically lowest 1,3 -isomer. This value amounts to approximately one third of the experimental value for the bond separation energy of pyridine. In all cases the energetically lowest triplet states are significantly $(16-24 \mathrm{kcal} / \mathrm{mol})$ higher in energy than the singlet ground states. Also among the triplets the 1,3-isomer is the energetically most fabourable species.
\end{abstract}

Key words: Diborabenzenes; Calculations; Singlet-Triplet Splitting; Relative Stabilities; Bond Separation Reactions.

\section{Introduction}

Although a huge number of experimental and theoretical papers on borabenzene $(\mathbf{4}$, borinine, see Scheme 1) have been published so far [1-10] very little is known about the compounds which have two boron atoms in the six-membered ring and which, therefore, might be called diborabenzenes $(\mathbf{1}-\mathbf{3}$, Scheme 1). Especially, the unsubstituted compounds of sum formula $\mathrm{C}_{4} \mathrm{H}_{4} \mathrm{~B}_{2}$ are apparently unknown so far, while some derivatives have been studied under various conditions by several groups. Thus, the electron spin resonance (ESR) spectrum of the radical anion of 2,3,5,6-tetramethyl-1,4-diborabenzene was published by Bock and coworkers already in 1980 [11].
Pioneering work in the field of the synthetic chemistry of the diborabenzenes was done by Herberich and coworkers who published a triple-decked sandwich complex of rhodium with a derivative of 1,4diborabenzene as bridging ligand one year later [12]. In 1986 a paper from the same group described the Li salt of a substituted 1,2-diboratabenzene [13], and a more detailed account of their work describing some 1,2dibora-3,5-cyclohexadiene metal complexes besides other compounds appeared in 1988 [14]. Moreover, the first derivative of 1,3-diborabenzene as a ligand in an iron complex could structurally be characterized in 1989 [15]. More transition metal complexes with ligands that can also be considered derivatives of 1,4diborabenzene have been described by Siebert et al. in 
2<smiles>CB1BBC=CC=CB1</smiles><smiles>B1=CC=CC=BB1</smiles><smiles>b1ccccc1</smiles>

3<smiles>c1ccccc1</smiles>

4<smiles>C=C1POC(C)C(C)C1=O</smiles>

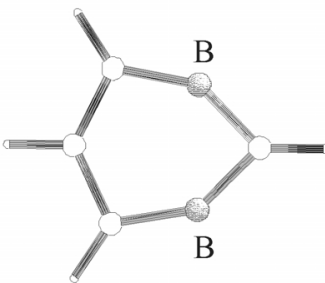

2

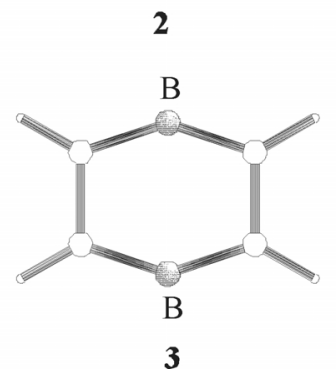

3

1
Scheme 1.

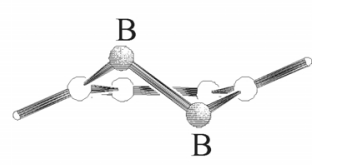

Fig. 1. Structures of the singlet ground states of the three isomers of diborabenzene optimized at the MP2/6-311++G** level of theory $\left(1: C_{2}, 2: C_{2 \mathrm{v}}, 3: D_{2 \mathrm{~h}}\right)$. All shown structures are local minima on the $\mathrm{C}_{4} \mathrm{H}_{4} \mathrm{~B}_{2}$ energy surface.

1987 [16]. However, as far as the authors are aware the unsubstituted compounds remain elusive so far.

Several reasons might account for the elusiveness of the title compounds. Firstly, the three unsubstituted uncharged borabenzenes might be no stationary points on the $\mathrm{C}_{4} \mathrm{H}_{4} \mathrm{~B}_{2}$ energy surface. Moreover, the molecules
Table 1. Selected structural parameters of 1,2-diborabenzene (1, planar $C_{2 \mathrm{v}}$, non-planar $\left.C_{2}\right)$, 1,3-diborabenzene $\left(2, C_{2 \mathrm{v}}\right)$, and 1,4-diborabenzene $\left(3, D_{2 \mathrm{~h}}\right.$ singlet, $C_{2 \mathrm{v}}$ triplet) calculated at the MP2/6-311++G** level. The numbers in parentheses are the values for the lowest triplet states (bond lengths in $\AA$, bond angles in ${ }^{\circ}$ ). For numbering of atoms see Scheme 2.

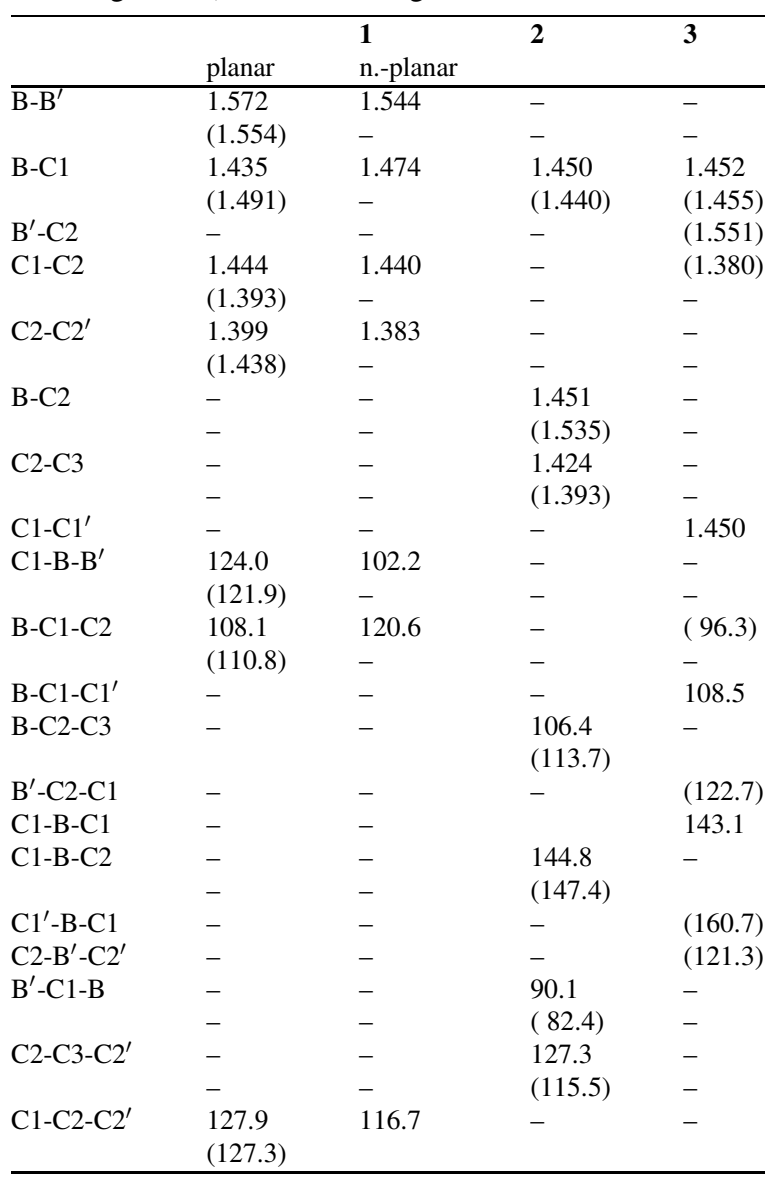

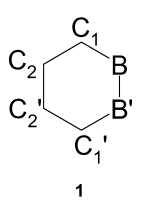<smiles>CC1[B]C[B][As]1C</smiles><smiles>B1CCCCC1</smiles>

3

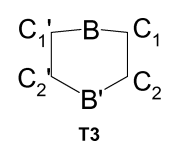

Scheme 2.

might be biradicals with highly reactive triplet ground states. In addition it is conceivable that the diborabenzenes are anti-Hückel systems with only two doubly occupied $\pi$ orbitals. Finally, like borabenzene [1,2] the ground states of all three diborabenzenes could be benzene-like closed shell singlet structures with six 
Table 2. Relative energies of the ground states of 1,2-diborabenzene (1) $)^{\mathrm{II}}, 1,3$-diborabenzene (2), and 1,4-diborabenzene (3) at different levels of theory (in $\mathrm{kcal} / \mathrm{mol}$ ).

\begin{tabular}{|c|c|c|c|}
\hline & $\mathbf{1}$ & 2 & 3 \\
\hline $\mathrm{HF} / 6-31+\mathrm{G}^{*} / / \mathrm{HF} / 6-31+\mathrm{G}^{*}$ & 38.87 & 0.00 & 21.79 \\
\hline $\mathrm{ZPE}^{\dagger}+\mathrm{HF} / 6-31+\mathrm{G}^{*} / / \mathrm{HF} / 6-31+\mathrm{G}^{*}$ & 39.71 & 0.00 & 21.72 \\
\hline MP2/6-311++G**//MP2/6-311++G** & 36.28 & 0.00 & 18.79 \\
\hline $\mathrm{ZPE}^{\#}+\mathrm{MP} 2 / 6-311++\mathrm{G}^{* *} / / \mathrm{MP} 2 / 6-311++\mathrm{G}^{* *}$ & 37.05 & 0.00 & 18.25 \\
\hline CCSD(T)/aug-cc-pVTZ//MP2/6-311++G** & 34.01 & 0.00 & 19.34 \\
\hline $\mathrm{ZPE}^{\#}+\mathrm{CCSD}(\mathrm{T}) /$ aug-cc-pVTZ//MP2/6-311++G* $* *$ & 34.78 & 0.00 & 18.80 \\
\hline $\mathrm{ZPE}^{\#}+\mathrm{CCSD}(\mathrm{T}) /$ infinite $^{\$} / / \mathrm{MP} 2 / 6-311++\mathrm{G}^{* *}$ & 35.77 & 0.00 & 19.31 \\
\hline CASSCF(6,7)aug-cc-pVTZ//MP2/6-311++G** & 30.11 & 0.00 & 15.41 \\
\hline
\end{tabular}

II Non-planar form. ${ }^{\dagger}$ Calculated at the HF/6-31+G* level. ${ }^{\#}$ Calculated at the MP2/6-311++G** level. ${ }^{\$}$ Infinite basis set extrapolation.

electrons in three orbitals of $\pi$ symmetry and a lowlying LUMO of $\sigma$ symmetry which causes strong acceptor properties and, therefore, high reactivity.

In order to gain some insight into the electronic and the geometric structure of the title compounds we performed quantum-chemical ab initio calculations on different levels of theory for three possible isomers of diborabenzene, where we considered only such structures on the $\mathrm{C}_{4} \mathrm{H}_{4} \mathrm{~B}_{2}$ energy surface where both boron atoms are members of the six-membered ring.

\section{Computational Methods}

The structures of the singlet states of all molecules under consideration were preoptimized at the restricted Hartree-Fock level using the $6-31+\mathrm{G}^{*}$ basis set. Starting from the resulting geometric parameters further optimizations were performed at the MP2 ${ }^{1}$ level employing the $6-311++\mathrm{G}^{* *}$ basis set which is the 6$311 \mathrm{G}$ contraction ${ }^{2}$ of gaussian functions by Krishnan et al. [17] augmented with a set of three $p$ like functions on hydrogen, a set of five $d$-like functions at boron and carbon, one set of diffuse $s$ and $p$ functions at the heavy atoms, and one set of diffuse $s$ functions at the hydrogen atoms. Calculations for the lowest triplet states of the molecules were performed with the unrestricted MP2 method (UMP2) and the $6-311++\mathrm{G}^{* *}$ basis set. All structures optimized at one of these levels were characterized as either local minima or saddle points by calculation and diagonalization of the corresponding force constant matrix. Using the MP2/6-311++ $\mathrm{G}^{* *}$-optimized structures single point calculations with the $\operatorname{CCSD}(\mathrm{T})^{1}$ method [18-22] were then carried out using Dunning's correlation consistent aug-cc-pVTZ basis set with a triple

\footnotetext{
${ }^{1}$ The correlation energy was calculated excluding the core electrons ("frozen core" approximation).

${ }^{2}(11 s 5 p / 5 s) \rightarrow[4 s 3 p / 3 s]$
}

split in the valence shells and containing diffuse (aug, one $s$, one $p$, and one $d$ diffuse function on hydrogen and one $s$, one $p$, one $d$, and one $f$ diffuse function on boron and carbon) ${ }^{3}$ [23-27]. An infinite basis set extrapolation was applied at the $\operatorname{CCSD}(\mathrm{T})$ level using the method of Truhlar [28,29]. Finally we performed $\operatorname{CASSCF}(6,7)$ calculations employing the MP2-6-311++G**-optimized structures and the augcc-pVTZ basis set, where the active space was chosen as described below. All calculations were performed using the Gaussian03 [30] suite of quantum-chemical programs. Total energies of all species under consideration obtained at different levels of theory are given in Table A1 (singlets) and A2 (triplets) of the appendix.

\section{Results and Discussion}

All three diborabenzenes were found to be minima on the $\mathrm{C}_{4} \mathrm{H}_{4} \mathrm{~B}_{2}$ energy surface. The optimized structures of the singlet states of all three isomers are shown in Figure 1, and selected structural parameters are given in Table 1. Relative energies obtained at different level on theory are collected in Table 2.

The corresponding total energies are given in Table A1 of the appendix.

At all levels of theory planar 1,3-diborabenzene (2) is the energetically lowest singlet species. The optimized structure has $C_{2 \mathrm{v}}$ symmetry and calculation and diagonalization of the corresponding force constant matrix showed that the structure displayed in Figure 1 is a local minimum. At the highest level of theory employed in this paper $(\mathrm{ZPE}+\mathrm{CCSD}(\mathrm{T}) / \mathrm{aug}$ cc-pVTZ//MP2/6-311++G**) 1,3-diborabenzene is about 34.8 and $18.8 \mathrm{kcal} / \mathrm{mol}$ lower in energy than the 1,2- and 1,4-isomer. Extrapolation to an infinite basis set slightly changed the relative energies to 35.8 and $19.3 \mathrm{kcal} / \mathrm{mol}$, respectively. At $1.450 \AA$ the two

\footnotetext{
${ }^{3}(11 s 6 p 3 d 2 f / 6 s 3 p 2 d) \rightarrow[5 s 4 p 3 d 2 f / 4 s 3 p 2 d]$
} 


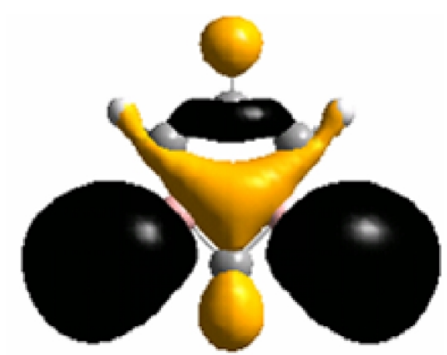

$\Psi_{20}$, LUMO

$+0.01570$
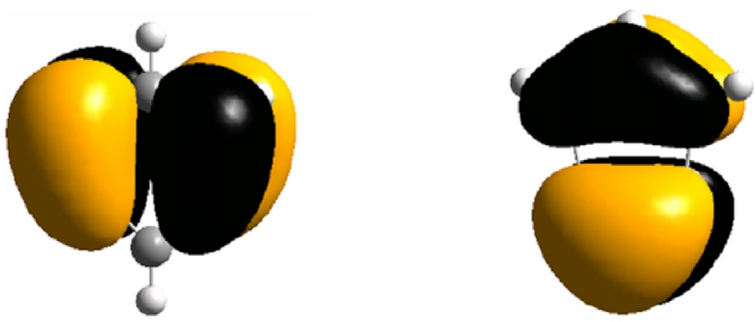

$\Psi_{19}$, HOMO $-0.29176$

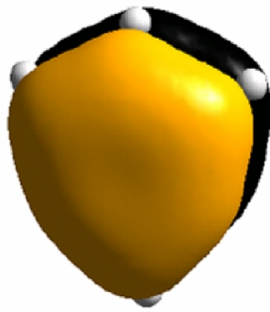

$\Psi_{17}, \underset{-0.47332}{\text { HOMO-2 }}$

Fig. 2. The three highest occupied $\left(\Psi_{17}-\Psi_{19}\right)$ and the lowest unoccupied $\left(\Psi_{20}\right)$ molecular orbitals of 1,3-diborabenzene. The numbers are the orbital energies in Hartrees.

$\mathrm{BC} 1$ bonds are only slightly longer than the $\mathrm{BC}$ bonds in borabenzene (4) at the same level of theory $(1.439 \AA)$. The $\mathrm{BC} 1$ bond lengths are closer to the average value $(1.475 \AA)$ of a C-B single $\left(\mathrm{H}_{2} \mathrm{~B}\right.$ $\mathrm{CH}_{3}, 1.562 \AA$ ) and double bond than to the value for an isolated $\mathrm{C}=\mathrm{B}$ double bond $\left(\mathrm{HB}=\mathrm{CH}_{2}, 1.387 \AA\right.$ ). The BC2 bonds are of essentially the same length $(1.451 \AA)$. Moreover, the CC bonds $(1.424 \AA)$ are also close to the average of a single and an isolated double bond (1.434 $\AA$ ). Thus the bond lengths in the ring show little alternation probably indicating a cer-
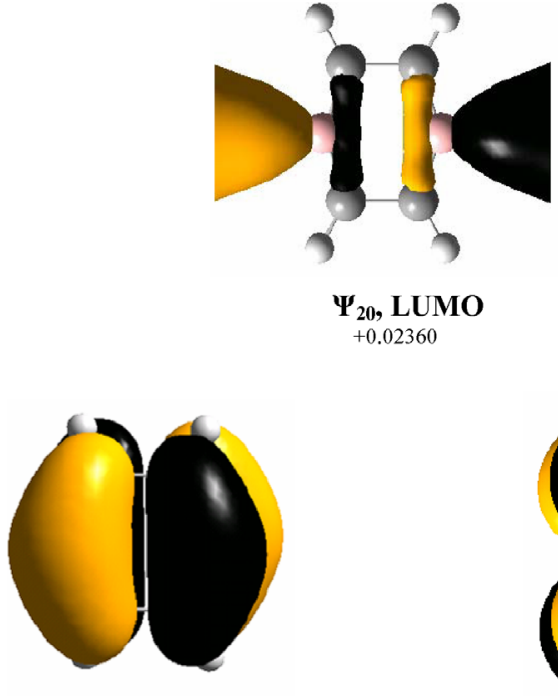

$\underset{-0.25850}{\Psi_{19}, \text { HOMO }}$

$\Psi_{18}$, HOMO-1

$-0.34139$

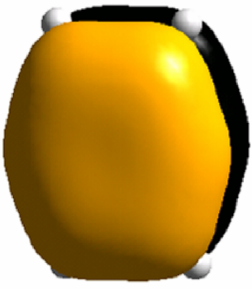

\section{$\Psi_{17}$, HOMO-2}

$-0.46385$

Fig. 3. The three highest occupied $\left(\Psi_{17}-\Psi_{19}\right)$ and the lowest unoccupied $\left(\Psi_{20}\right)$ molecular orbitals of 1,4-diborabenzene. The numbers are the orbital energies in Hartrees.

tain degree of delocalization. The C1-B-C2 bond angles are $144.8^{\circ}$ and, therefore, are even larger than the corresponding angle in $4\left(142.2^{\circ}\right)$. The B-C-B and and the C-C-C angles are 90.1 and $127.3^{\circ}$, respectively.

The next stable isomer is 1,4-diborabenzene (3). The optimized structure is also planar and has $D_{2 \mathrm{~h}}$ symmetry. At $143.1^{\circ}$ the C-B-C angles are somewhat smaller than the one in 2 . The lengths of the $\mathrm{BC}$ bonds $(1.452 \AA)$ are essentially the same as in the most stable isomer while the CC bond (1.450 $\AA$ ) is closer to a single than to a double bond. It appears that bond alternation is more pronounced in this isomer than in $\mathbf{2}$ which might indicate a lower degree of delocalization than in the most stable isomer 2. 


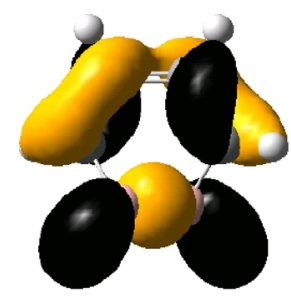

$\Psi_{20}$, LUMO

$+0.02175$

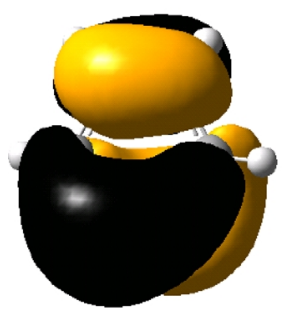

$\Psi_{19}$, HOMO

$-0.29772$

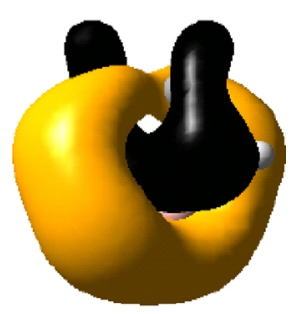

$\Psi_{18}$, HOMO-1

$-0.31951$

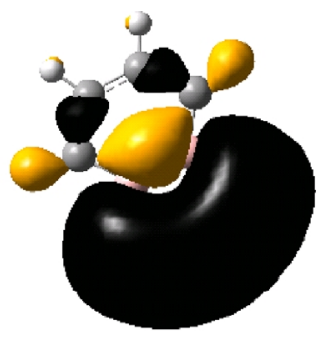

$\Psi_{20}$, LUMO

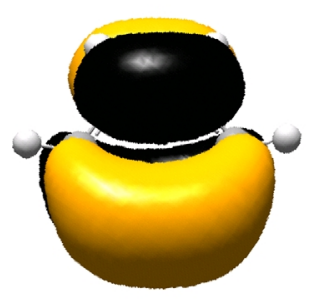

$\Psi_{19}$, HOMO

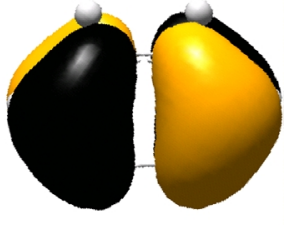

$\Psi_{18}$, HOMO-1

$-0.32460$

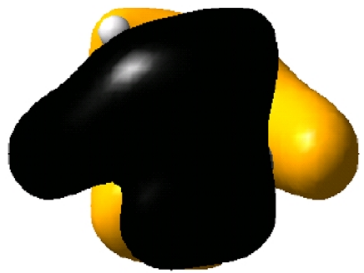

$\Psi_{17}$, HOMO-2

$-0.44720$

Fig. 4. The three highest occupied $\left(\Psi_{17}-\Psi_{19}\right)$ and the lowest unoccupied $\left(\Psi_{20}\right)$ molecular orbitals of non-planar 1,2-diborabenzene. The numbers are the orbital energies in Hartrees.

The least stable compound in this series is 1,2diborabenzene (1). The planar $C_{2 \mathrm{v}}$ structure is not a minimum but rather a saddle point with one imaginary frequency in the spectrum of its normal vibrations. It is $3.7 \mathrm{kcal} / \mathrm{mol}$ higher in energy than a non-planar structure of $C_{2}$ symmetry which corresponds to a local minimum. An infinit basis set extrapolation slightly reduces this energy difference to about $3 \mathrm{kcal} / \mathrm{mol}$. The BB bond length in this structure is $1.544 \AA$ and, therefore, shorter than the corresponding bond in the planar species (1.572 $\AA$ ). Thus the length of this bond in the

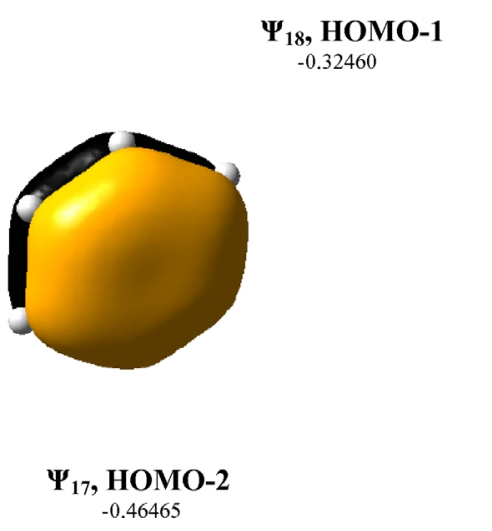

Fig. 5. The three highest occupied $\left(\Psi_{17}-\Psi_{19}\right)$ and the lowest unoccupied $\left(\Psi_{20}\right)$ molecular orbitals of planar 1,2diborabenzene. This structure is not a local minimum but a saddle point. The numbers are the orbital energies in Hartrees.

planar form is much closer to the $\mathrm{B}=\mathrm{B}$ double bond in $\mathrm{HB}=\mathrm{BH}(1.533 \AA)$ than to the $\mathrm{B}-\mathrm{B}$ single bond in $\mathrm{H}_{2} \mathrm{~B}$ $\mathrm{BH}_{2}(1.659 \AA)$. Moreover, the the CB bond lengths in non-planar 1 are $1.474 \AA$ and almost identical to the average value of a $\mathrm{B}-\mathrm{C}$ single and and $\mathrm{B}=\mathrm{C}$ double bond while at $1.440(\mathrm{C} 1 \mathrm{C} 2)$ and $1.383 \AA\left(\mathrm{C} 2 \mathrm{C} 2^{\prime}\right)$ the lengths of the two types of $\mathrm{CC}$ bonds differ significantly.

The 1,3-, 1,4- as well as the planar form of 1,2diborabenzene have three doubly occupied molecular orbitals of $\pi$ symmetry which resemble the $a_{2 u}$ and $e_{1 \mathrm{~g}}$ MOs of $D_{6 \mathrm{~h}}$ benzene. Non-planar 1 has also three 

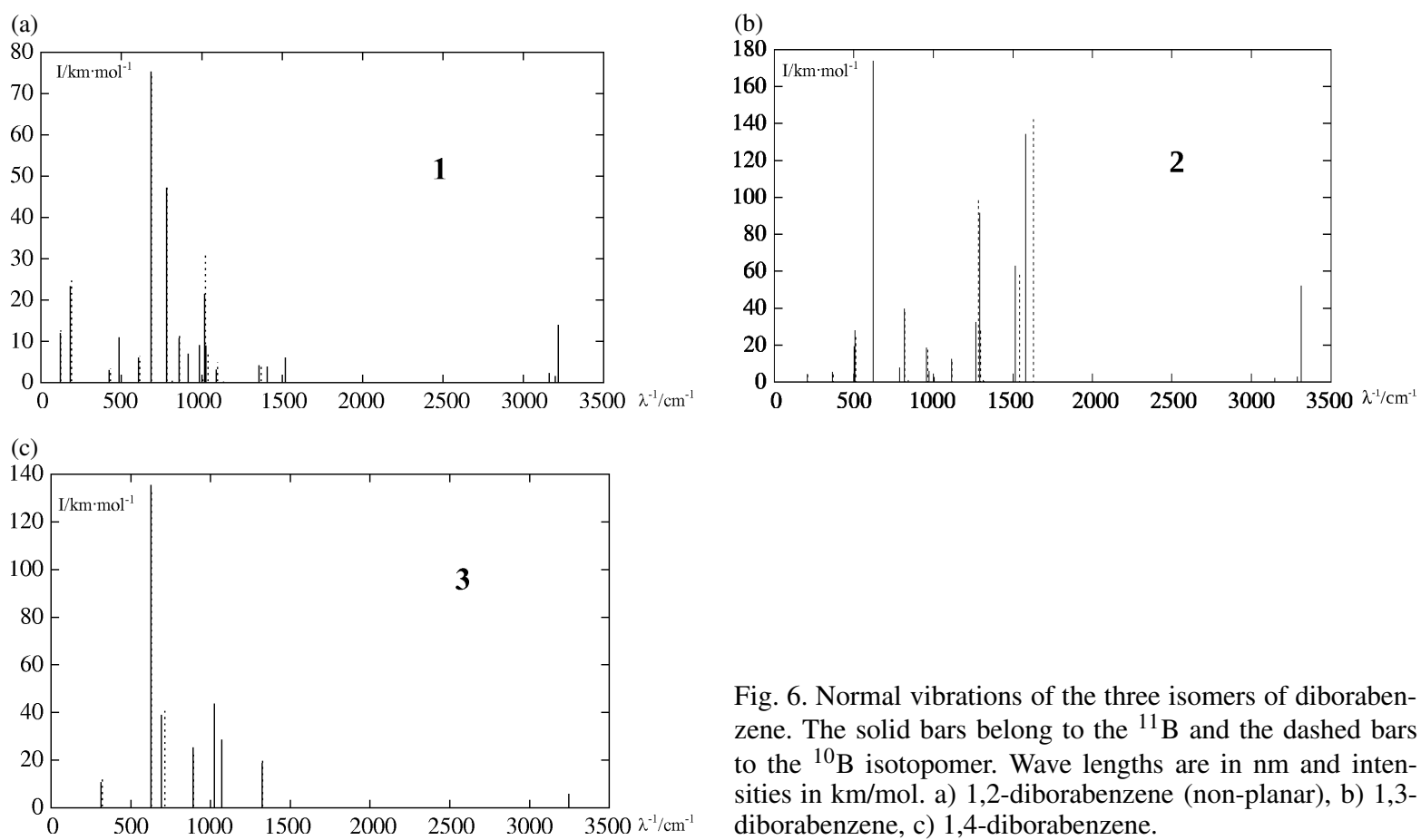

doubly occupied orbitals which can directly be derived from the $\pi$ orbitals of the planar form (Figs. 4 and 5). The lowest unoccupied orbitals $\left(\Psi_{20}\right)$ of all four stationary points have $\sigma$ symmetry with large coefficients at both boron atoms. At $0.0018-0.0236$ Hartrees these LUMOs are energetically lower than those of benzene (0.0299 Hartrees) and pyridine (0.0261 Hartrees). This situation is similar to the electronic structure of borabenzene, and these low-lying orbitals may be one of the reasons for an extremely high reactivity and, therefore, for the elusiveness of the parent diborabenzenes.

Starting from the HF/aug-cc-pVTZ MOs we performed $\operatorname{CASSCF}(6,7)$ calculations. The active space in the calculations on the singlets included the three doubly occupied orbitals of $\pi$ symmetry, the LUMO of $\sigma^{*}$ symmetry and three energetically lowest least diffuse $\pi^{*}$ orbitals showing the correct nodal properties. The results are also given in Tables 2 and A1, respectively. The order of stabilities obtained at the other levels of theory is retained in the $\operatorname{CASSCF}(6,7)$ calculations in that 2 remains the most stable isomer followed by 3 . Planar 1 remains the least stable species with the non-planar isomer being $3.5 \mathrm{kcal} / \mathrm{mol}$ lower in energy. At occupancies of less than 0.1 e the low-lying orbitals of $\sigma^{*}$ symmetry are essentially empty.

Fig. 6. Normal vibrations of the three isomers of diborabenzene. The solid bars belong to the ${ }^{11} \mathrm{~B}$ and the dashed bars to the ${ }^{10} \mathrm{~B}$ isotopomer. Wave lengths are in $\mathrm{nm}$ and intensities in $\mathrm{km} / \mathrm{mol}$. a) 1,2-diborabenzene (non-planar), b) 1,3diborabenzene, c) 1,4-diborabenzene.

The calculated vibrational frequencies which will be helpful to the experimentalist in identifying one of the species generated for example in a rare gas matrix are listed in Table A3 of the appendix and the corresponding spectra are plotted in Figure 6. Those vibrations in which the boron atoms participate significantly show a strong ${ }^{11} \mathrm{~B}-{ }^{10} \mathrm{~B}$ isotopic shift. The most important vibrations of the lower weight isotopomers $\left({ }^{10} \mathrm{~B}\right)$ are shown in Figure 6 as dashed bars.

The structures of the lowest triplet states of the three diborabenzenes obtained at the UMP2/6-311++G** level are plotted in Figure 7. All structures shown in this figure are planar $\left(C_{2 \mathrm{v}}\right)$ and correspond to local minima. Relative and total energies are given in Table 3 and Table A2 of the appendix where we also list the corresponding $\left\langle S^{2}\right\rangle$ values to estimate the contamination of the UMP2 triplets by higher spin states. All triplet states are energetically significantly less favourable than the corresponding singlets and at the ZPE+PUMP2/6-311++G**// UMP2/6-311++G** level their energies relative to the corresponding singlet ground states are 16.0, 20.3, and $24.0 \mathrm{kcal} / \mathrm{mol}$ for $\mathbf{T 1}, \mathbf{T 2}$, and $\mathbf{T 3}$, respectively. Striking structural feature of $\mathbf{T} 3$ are the two different $\mathrm{C}-\mathrm{B}-\mathrm{C}$ angles. At $160.7^{\circ} \mathrm{C} 1^{\prime}-\mathrm{B}-\mathrm{C}$ is the largest bond angle found in this study. Total and zero point energies 
Table 3. Relative energies of the lowest triplet states of 1,2- (T1), 1,3- (T2), and 1,4-diborabenzene (T3) (in kcal/mol).

\begin{tabular}{lccc}
\hline & T1 & T2 & T3 \\
\hline ZPE $^{\#}+\mathrm{PUMP} 2 / 6-311++\mathrm{G}^{* *} / / \mathrm{UMP} 2 / 6-311++\mathrm{G}^{* *}$ & 32.71 & 0.00 & 21.93 \\
& 15.97 & 20.31 & $23.99^{\text {II, }}$ \\
CASSCF(6,7)/aug-cc-pVTZ//UMP2/6-311++G** & 21.66 & 0.00 & 9.44 \\
& 9.57 & 18.02 & $12.05^{\text {II }}$ \\
CASSCF(6,7)/6-31G*//UMP2/6-311++G** & 22.04 & 0.00 & 9.47 \\
\hline
\end{tabular}

II Relative to the corresponding singlet ground state. ${ }^{\dagger}$ MP2 energies for singlets PUMP2 energies for triplets. ${ }^{\#}$ Calculated at the $\mathrm{UMP} 2 / 6-311++\mathrm{G}^{* *}$ level.<smiles>C=C1CC(C)=C(C)C1=C</smiles>

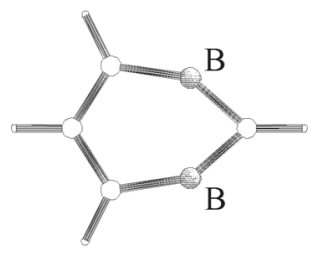

T2

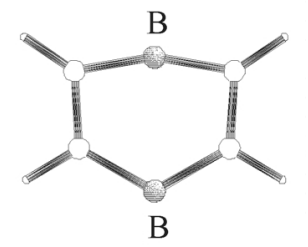

T3

Fig. 7. Structures of the lowest triplet states of the three isomers of diborabenzene optimized at the UMP2/6-311++G** level of theory $\left(\right.$ all $C_{2 \mathrm{v}}$ ). All shown structures are local minima on the $\mathrm{C}_{4} \mathrm{H}_{4} \mathrm{~B}_{2}$ energy surface.

are listed in Table A2 of the appendix. Like in the case of the singlets the 1,3 isomer (T2) is the most and the 1,2 isomer the (T1) the least stable isomer.

Starting from the ROMP2/6-31G* and ROMP2/ aug-cc-pVTZ wave functions we also performed CASSCF calculations for the lowest triplet states of the three diborabenzenes where the active space comprised the two doubly- $(\pi)$ and the two singly-occupied orbitals $\left(\pi, \sigma^{*}\right)$, as well as the energetically lowest least diffuse orbitals of $\pi^{*}$ symmetry with the correct nodal structures. Relative and total energies obtained at the CASSCF level are also given in Tables 3 and Table A2, respectively. As with the other methods and as among the singlets the 1,3-isomer is the most stable species.

$$
\|_{\mathrm{B}-\mathrm{B}}+\begin{aligned}
& 2 \mathrm{BH}_{3}+4 \mathrm{CH}_{4} \longrightarrow \\
& 2 \mathrm{H}_{3} \mathrm{C}-\mathrm{CH}_{3}+\mathrm{H}_{2} \mathrm{C}=\mathrm{CH}_{2} \\
& +2 \mathrm{HB}=\mathrm{CH}_{2}+2 \mathrm{H}_{2} \mathrm{~B}-\mathrm{BH}_{2}
\end{aligned}
$$

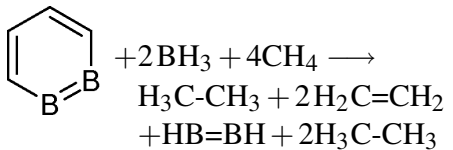<smiles>b1cbccc1</smiles>

$$
\begin{aligned}
& +2 \mathrm{BH}_{3}+4 \mathrm{CH}_{4} \longrightarrow \\
& \mathrm{H}_{3} \mathrm{C}-\mathrm{CH}_{3}+\mathrm{H}_{2} \mathrm{C}=\mathrm{CH}_{2}
\end{aligned}
$$$$
+2 \mathrm{HB}=\mathrm{CH}_{2}+2 \mathrm{H}_{2} \mathrm{~B}-\mathrm{BH}_{2}
$$<smiles>b1ccccc1</smiles>

$$
\begin{aligned}
& +2 \mathrm{BH}_{3}+4 \mathrm{CH}_{4} \longrightarrow \\
& \mathrm{H}_{3} \mathrm{C}-\mathrm{CH}_{3}+\mathrm{H}_{2} \mathrm{C}=\mathrm{CH}_{2}
\end{aligned}
$$$$
+2 \mathrm{HB}=\mathrm{CH}_{2}+2 \mathrm{H}_{2} \mathrm{~B}-\mathrm{BH}_{2}
$$

Scheme 3.

Moreover, all triplets are energetically between 10 and $18 \mathrm{kcal} / \mathrm{mol}$ above the singlet ground states. However, at the CASSCF level the energy difference between the 1,3- on the one, and the 1,2- and the 1,4-isomer on the other hand are about 22 and $9 \mathrm{kcal} / \mathrm{mol}$ and thus more than $10 \mathrm{kcal} / \mathrm{mol}$ less than at the PUMP2 level. Identification of the correct unoccupied orbitals for the active space is complicated by the diffuse components of the aug-cc-pVTZ basis set. To make sure that the differences to the PUMP2 energies are not due to an erroneous definition of the active space we repeated the calculations using the same geometry but the $6-31 \mathrm{G}^{*}$ basis set instead. In this way we obtained essentially the same results as with the much larger correlationconsistant basis set. We are currently unable to provide a conclusive explanation as to the differenced between the PUMP2 and the CASSCF results for the triplets.

Isodesmic bond separation reactions [31-33] have been used to evaluate the stabilization or destabilization of the molecules relative to their fragments due to cyclic conjugation (Scheme 3). Depending on the choice of the mesomeric form (A or B, Scheme 1) two 
different reactions have to be considered (1a), (1b) in the case of the 1,2-isomer while one single reaction is sufficient in the case of 1,3- and 1,4-diborabenzene (2), (3). The energies have been calculated at the CCSD(T)/aug-cc-pVTZ//MP2/6-311++G** level including the zero point energy calculated with the MP2/6-311++G** method. All bond separation energies are positive ((1)1a: 3.6; (1)1b: 19.9; (2)2: 23.6; (3)3: $4.8 \mathrm{kcal} / \mathrm{mol}$ ) indicating that cyclic conjugative interaction between the fragments stabelizes the three cyclic compounds relative to the corresponding isolated fragments. The corresponding value for borabenzene at the same level of theory is $37.6 \mathrm{kcal} / \mathrm{mol}$. The most effective stabilization of $23.6 \mathrm{kcal} / \mathrm{mol}$ was calculated for 1,3-diborabenzene. Although it is much lower than the experimental values for some typical aromatics (benzene 64.2, pyridine 71.9, pyridazine $74.6^{4}$, pyrimidine 80.4 , and pyrazine $80.5 \mathrm{kcal} / \mathrm{mol}$ [31]) it is comparable to the experimental bond separation en-

${ }^{4}$ employing the mesomeric form with a N-N single bond. ergy of cyclopentadiene $\left(22.4 \mathrm{kcal} / \mathrm{mol}[33]^{5}\right)$. Moreover, the energy of bond separation is more than five times higher for reaction $1 \mathrm{~b}$ than for $1 \mathrm{a}$ indicating that according to these model reactions cyclic conjugation between one $\mathrm{B}=\mathrm{B}$ and two $\mathrm{C}=\mathrm{C}$ double bonds is energetically more favourable than between two $\mathrm{B}=\mathrm{C}$ and one $\mathrm{C}=\mathrm{C}$ bond. This is also reflected by the calculated structure of non-planar 1,2-diborabenzene which, as far as the bond lengths are concerned, is much closer to a structure like $\mathbf{A}$ than to one like $\mathbf{B}$ (Scheme 1). Thus, as mentioned above the distance between the two boron atoms in the optimized structure of 1,2diborabenzene is much closer to the value for a $\mathrm{B}=\mathrm{B}$ double than for a B-B single bond (vide supra).

\section{Conclusions}

Quantum-chemical calculations performed at different levels of theory show that all three diborabenzens have singlet ground states with six electrons in three

\footnotetext{
${ }^{5}$ Ref. [33] Table 6.71, p. $302-303$.
}

\section{Appendix}

Table A1. Total energies and zero point energies (in Hartrees) of all the three singlet diborabenzenes and of the fragment molecules used in the bond separation reactions.

\begin{tabular}{|c|c|c|c|c|c|}
\hline Molecule & $\begin{array}{l}\text { MP2/6-311++G**// } \\
\text { MP2/6-311++G** }\end{array}$ & $\mathrm{ZPE}^{\mathbb{I I}}$ & $\begin{array}{l}\text { CCSD(T)/ aug-cc-pVTZ // } \\
\text { MP2/6-311++G** }\end{array}$ & $\begin{array}{l}\text { CCSD(T)/infinite }{ }^{\ddagger} / / \\
\text { MP2/6-311++G** }\end{array}$ & $\begin{array}{l}\text { CASSCF }(6,7) / \\
\text { aug-cc-pVTZ// } \\
\text { MP2/6-311++G** }\end{array}$ \\
\hline \multirow[t]{2}{*}{ 1,2-Diborabenzene (1) } & -203.747399 & 0.069938 & -203.956223 & -204.071208 & -203.126122 \\
\hline & $(-203.742441$ & 0.067979 & -203.950337 & -204.066362 & $-203.120527)^{\dagger}$ \\
\hline 1,3-Diborabenzene (2) & -203.805215 & 0.068709 & -204.010415 & -204.126982 & -203.174108 \\
\hline 1,4-Diborabenzene (3) & -203.775268 & 0.067851 & -203.979602 & -204.095347 & -203.149550 \\
\hline $\mathrm{BH}_{3}$ & -26.494887 & 0.026707 & -26.539081 & & \\
\hline $\mathrm{CH}_{4}$ & -40.379638 & 0.045404 & -40.440929 & & \\
\hline $\mathrm{HB}=\mathrm{BH}^{\#}$ & -50.533813 & 0.021039 & -50.603989 & & \\
\hline $\mathrm{H}_{2} \mathrm{~B}-\mathrm{BH}_{2}{ }^{\$}$ & -51.822513 & 0.039273 & -51.899740 & & \\
\hline $\mathrm{HB}=\mathrm{CH}_{2} \neq$ & -64.465957 & 0.033468 & -64.546236 & & \\
\hline $\mathrm{H}_{3} \mathrm{C}-\mathrm{BH}_{2} \int$ & -65.708939 & 0.056481 & -65.800646 & & \\
\hline $\mathrm{H}_{2} \mathrm{C}=\mathrm{CH}_{2}$ & -78.346528 & 0.050805 & -78.443756 & & \\
\hline $\mathrm{H}_{3} \mathrm{C}-\mathrm{CH}_{3}$ & -79.571671 & 0.075757 & -79.679947 & & \\
\hline
\end{tabular}

II For MP2/6-311++G**-optimized geometries, ${ }^{\dagger}$ planar form, ${ }^{\#} \mathrm{~B}=\mathrm{B}: 1.533 \AA$ А, ${ }^{\$} \mathrm{~B}-\mathrm{B}: 1.659 \AA{ }^{\neq} \neq \mathrm{B}=\mathrm{C}: 1.387 \AA{ }^{\jmath} \mathrm{B}-\mathrm{C}: 1.562 \AA .{ }^{£}$ Infinite basis set approximation.

Table A2. Total energies and zero point energies (in Hartrees) of all the lowest triplet states of the three diborabenzenes. The numbers in parentheses are the values before spin projection (UMP2/6-311++G**).

\begin{tabular}{lllll}
\hline Molecule & PUMP2/6-311++G**// & ZPE II & $\left\langle S^{2}\right\rangle$ & $\begin{array}{l}\text { CASSCF(6,7)/aug-cc-pVTZ// } \\
\text { UMP2/6-311++G** }\end{array}$ \\
\hline 1,2-Diborabenzene (T1) & -203.733258 & & -203.110868 \\
& $(-203.727629)$ & 0.081250 & $(2.099)$ & -203.145393 \\
1,3-Diborabenzene (T2) & -203.773387 & & 2.020 & -203.130343 \\
& $(-203.760844)$ & 0.069248 & $(2.232)$ & \\
1,4-Diborabenzene (T3) & -203.739654 & & 2.002 & $(2.067)$ \\
& $(-203.736439)$ & 0.070461 & & \\
\hline
\end{tabular}

I For UMP2/6-311++G**-optimized geometries. 
Table A3. Calculated (MP2/6-311++ $\mathrm{G}^{* *}$ ) normal frequencies of the ${ }^{10} \mathrm{~B}$ and ${ }^{11} \mathrm{~B}$ isotopomers of singlets $1,2-$, 1,3-, and 1,4-diborabenzene. Wave numbers in $\mathrm{cm}^{-1}$, IR intensities in $\mathrm{km} / \mathrm{mole}$.

\begin{tabular}{|c|c|c|c|c|c|c|c|c|c|c|c|c|c|c|c|c|c|}
\hline \multirow{3}{*}{123.0} & \multicolumn{5}{|c|}{$\mathbf{1}\left(C_{2}\right)$} & \multicolumn{6}{|c|}{$\mathbf{2}\left(C_{2 \mathrm{v}}\right)$} & \multicolumn{6}{|c|}{$\mathbf{3}\left(D_{2 h}\right)$} \\
\hline & \multicolumn{2}{|l|}{${ }^{10} \mathrm{~B}$} & \multicolumn{3}{|c|}{${ }^{11} \mathrm{~B}$} & \multicolumn{3}{|c|}{${ }^{10} \mathrm{~B}$} & \multicolumn{3}{|c|}{${ }^{11} \mathrm{~B}$} & \multicolumn{3}{|c|}{${ }^{10} \mathrm{~B}$} & \multicolumn{3}{|c|}{${ }^{11} \mathrm{~B}$} \\
\hline & 12.6 & $\bar{B}$ & 119.6 & 11.9 & $B$ & 210.0 & 4.2 & $B_{1}$ & 209.2 & 4.2 & $B_{1}$ & 191.4 & 0.0 & $B_{2 g}$ & 186.8 & 0.0 & $\overline{B_{2 g}}$ \\
\hline 188.6 & 24.8 & $A$ & 182.9 & 23.4 & $A$ & 367.5 & 0.0 & $A_{2}$ & 356.1 & 0.0 & $A_{2}$ & 281.2 & 0.0 & $B_{3 \mathrm{~g}}$ & 279.5 & 0.0 & $B_{3 g}$ \\
\hline 430.4 & 3.4 & $B$ & 423.0 & 3.1 & $B$ & 372.3 & 6.3 & $B_{1}$ & 366.4 & 5.1 & $B_{1}$ & 321.2 & 12.1 & $B_{3 \mathrm{u}}$ & 311.6 & 10.8 & $B_{3 \mathrm{u}}$ \\
\hline 485.6 & 10.9 & $A$ & 484.3 & 10.9 & $A$ & 460.0 & 0.0 & $B_{2}$ & 447.5 & 0.0 & $B_{2}$ & 376.7 & 0.0 & $A_{\mathrm{u}}$ & 376.7 & 0.0 & $A_{\mathrm{u}}$ \\
\hline 614.1 & 6.4 & A & 605.2 & 6.0 & $A$ & 506.3 & 19.6 & $A_{1}$ & 502.3 & 19.1 & $A_{1}$ & 498.2 & 0.0 & $B_{1 \mathrm{~g}}$ & 498.2 & 0.0 & $B_{1 \mathrm{~g}}$ \\
\hline 685.7 & 74.5 & $B$ & 684.4 & 75.3 & $B$ & 511.8 & 25.8 & $B_{1}$ & 507.4 & 27.8 & $B_{1}$ & 627.9 & 134.2 & $B_{3 \mathrm{u}}$ & 614.0 & 0.0 & $A_{\mathrm{g}}$ \\
\hline 782.5 & 47.6 & $B$ & 781.6 & 47.1 & $B$ & 620.8 & 174.6 & $B_{1}$ & 620.6 & 173.6 & $B_{1}$ & 634.7 & 0.0 & $A_{\mathrm{g}}$ & 625.4 & 135.5 & $B_{3 \mathrm{u}}$ \\
\hline 817.9 & 0.3 & A & 816.5 & 0.4 & $A$ & 652.8 & 0.0 & $A_{2}$ & 651.8 & 0.0 & $A_{2}$ & 690.8 & 0.0 & $B_{2 \mathrm{~g}}$ & 690.6 & 0.0 & $B_{2 \mathrm{~g}}$ \\
\hline 860.5 & 11.8 & $B$ & 859.6 & 10.8 & $B$ & 818.9 & 7.4 & $A_{1}$ & 788.3 & 7.7 & $A_{1}$ & 714.3 & 42.5 & $B_{1 \mathrm{u}}$ & 692.2 & 38.9 & $B_{1 \mathrm{u}}$ \\
\hline 914.7 & 6.8 & $A$ & 914.6 & 6.9 & $A$ & 819.1 & 39.5 & $B_{2}$ & 818.8 & 39.3 & $B_{2}$ & 780.3 & 0.0 & $A_{\mathrm{u}}$ & 780.3 & 0.0 & $A_{\mathrm{u}}$ \\
\hline 1006.3 & 1.0 & $A$ & 984.2 & 9.1 & $A$ & 841.3 & 0.8 & $B_{1}$ & 841.3 & 0.8 & $B_{1}$ & 892.6 & 23.3 & $B_{\mathrm{u}}$ & 891.4 & 25.3 & $B_{1 \mathrm{u}}$ \\
\hline 1021.9 & 31.5 & $A$ & 1017.4 & 21.5 & $A$ & 963.6 & 17.5 & $B_{2}$ & 955.2 & 18.5 & $B_{2}$ & 935.2 & 0.0 & $A_{\mathrm{g}}$ & 925.0 & 0.0 & $A_{\mathrm{g}}$ \\
\hline 1037.5 & 7.0 & $B$ & 1025.0 & 9.0 & $B$ & 973.0 & 5.6 & $A_{1}$ & 971.5 & 5.8 & $A_{1}$ & 1022.9 & 43.8 & $B_{2 \mathrm{u}}^{\mathrm{g}}$ & 1022.8 & 43.6 & $B_{2 \mathrm{u}}^{g}$ \\
\hline 1098.4 & 4.9 & $B$ & 1090.7 & 3.2 & $B$ & 1004.2 & 2.3 & $A_{1}$ & 1003.8 & 2.4 & $A_{1}$ & 1065.7 & 0.0 & $A_{\mathrm{g}}$ & 1063.6 & 0.0 & $A_{\mathrm{g}}$ \\
\hline 1135.9 & 0.1 & A & 1134.4 & 0.2 & $A$ & 1117.0 & 12.7 & $B_{2}$ & 1114.8 & 12.3 & $B_{2}$ & 1070.0 & 28.4 & $B_{2 \mathrm{u}}$ & 1069.8 & 28.6 & $B_{2 \mathrm{u}}$ \\
\hline 1234.7 & 0.1 & A & 1199.4 & 0.0 & $A$ & 1283.2 & 100.4 & $B_{2}$ & 1266.5 & 32.1 & $B_{2}$ & 1196.8 & 0.0 & $B_{3 \mathrm{~g}}$ & 1189.0 & 0.0 & $B_{3 \mathrm{~g}}$ \\
\hline 1368.4 & 4.4 & $B$ & 1356.0 & 0.4 & $A$ & 1297.1 & 28.8 & $B_{2}$ & 1291.3 & 91.2 & $B_{2}$ & 1267.3 & 0.0 & $A_{\mathrm{g}}$ & 1264.8 & 0.0 & $A_{\mathrm{g}}$ \\
\hline 1377.1 & 0.3 & A & 1357.2 & 4.1 & $B$ & 1316.9 & 1.7 & $A_{1}$ & 1311.8 & 0.7 & $A_{1}$ & 1325.5 & 19.7 & $B_{1 \mathrm{u}}$ & 1323.5 & 18.8 & $B_{1 \mathrm{u}}$ \\
\hline 1407.7 & 3.4 & $B$ & 1406.1 & 3.9 & $B$ & 1540.9 & 59.2 & $B_{2}$ & 1515.3 & 62.5 & $B_{2}$ & 1482.7 & 0.2 & $B_{2 \mathrm{u}}$ & 1433.1 & 0.2 & $B_{2 \mathrm{u}}$ \\
\hline 1520.3 & 6.0 & A & 1518.8 & 6.0 & $A$ & 1629.7 & 143.0 & $A_{1}$ & 1580.9 & 134.1 & $A_{1}$ & 1629.5 & 0.0 & $B_{3 \mathrm{~g}}$ & 1585.7 & 0.0 & $B_{3 \mathrm{~g}}$ \\
\hline 3161.3 & 1.1 & $B$ & 3161.3 & 1.1 & $B$ & 3147.3 & 1.9 & $A_{1}$ & 3147.3 & 1.9 & $A_{1}$ & 3232.7 & 0.1 & $B_{1 \mathrm{u}}$ & 3232.7 & 0.1 & $B_{1 \mathrm{u}}$ \\
\hline 3161.9 & 2.3 & $A$ & 3161.9 & 2.3 & $A$ & 3289.8 & 0.4 & $A_{1}$ & 3289.7 & 0.4 & $A_{1}$ & 3235.3 & 0.0 & $B_{3 \mathrm{~g}}$ & 3235.2 & 0.0 & $B_{3 \mathrm{~g}}$ \\
\hline 3198.2 & 1.6 & B & 3198.2 & 1.6 & $B$ & 3290.0 & 2.6 & $B_{2}$ & 3289.9 & 2.6 & $B_{2}$ & 3245.0 & 0.0 & $A_{\mathrm{g}}$ & 3245.0 & 0.0 & $A_{\mathrm{g}}$ \\
\hline 3217.3 & 14.0 & $A$ & 3217.3 & 14.0 & A & 3312.3 & 52.4 & $A_{1}$ & 3312.2 & 51.9 & $A_{1}$ & 3246.4 & 5.9 & $B_{2 \mathrm{u}}$ & 3246.3 & 5.9 & $B_{2 \mathrm{u}}$ \\
\hline
\end{tabular}

doubly occupied orbitals of $\pi$ or $\pi$-like symmetry. Planar 1,3-diborabenzene was found to be the most stable structure separated from the 1,4 and 1,2 isomer by energy gaps of 18.8 and $34.8 \mathrm{kcal} / \mathrm{mol}$, respectively. All three compounds are stabilized relative to their frag- ments by cyclic conjugation with the most effective stabilization $(23.6 \mathrm{kcal} / \mathrm{mol})$ found for the energetically lowest isomer. At the PUMP2 level corresponding triplet states are $16-24 \mathrm{kcal} / \mathrm{mol}$ higher in energy, and here too the 1,3 isomer is lowest in energy.
[1] G. Raabe, E. Heyne, W. Schleker, and J. Fleischhauer, Z. Naturforsch. 39a, 678 (1984).

[2] G. Raabe, W. Schleker, E. Heyne, and J. Fleischhauer, Z. Naturforsch. 42a, 352 (1987).

[3] J. M. Schulman and R. L. Disch, Organomet. 8, 733 (1989).

[4] J. Cioslowski and P. J. Hay, J. Am. Chem. Soc. 112, 1707 (1990).

[5] M. C. Böhm, U. Schmitt, and J. Schütt, J. Phys. Chem. 97, 11427 (1993).

[6] P. B. Karadakov, M. Ellis, J. Gerratt, D. L. Cooper, and M. Raimondi, Int. J. Quantum Chem. 63, 441 (1997).

[7] S. G. Semenov and Y. F. Sigolaev, Russ. J. Gen. Chem. 76, 580 (2006).

[8] G. Maier, H.P. Reisenauer, J. Henkelmann, and C. Kliche, Angew. Chem. Int. Ed. Engl. 27, 295 (1988).

[9] R. Boese, N. Finke, J. Henkelmann, G. Maier, P. Paetzold, H. P. Reisenauer, and G. Schmid, Chem. Ber. 118, 1644 (1985).
[10] G. Maier, Pure \& Appl. Chem. 58, 95 (1986).

[11] W. Kaim, H. Bock, P. Hawker, and P.L. Timms, J. Chem. Soc. Chem. Commun. 577 (1980).

[12] G. E. Herberich, B. Heßner, G. Huttner, and L. Zsolnai, Angew. Chem. 93, 471 (1981); Angew. Chem. Int. Ed. Engl. 20, 472 (1981).

[13] G. E. Herberich, B. Heßner, and M. Hostalek, Angew. Chem. 98, 637 (1986); Angew. Chem. Int. Ed. Engl. 25, 642 (1986).

[14] G. E. Herberich, B. Hessner, and M. Hostalek, J. Organomet. Chem. 355, 473 (1988).

[15] G. E. Herberich, B. Hessner, N. Klaff, and H. Ohst, J. Organomet. Chem. 375, 161 (1989).

[16] W. Siebert, Pure \& Appl. Chem. 59, 947 (1987).

[17] R. Krishnan, J. S. Binkley, R. Seeger, and J. A. Pople, J. Chem. Phys. 72, 650 (1980).

[18] J. Cizek, Adv. Chem. Phys. 14, 35 (1969).

[19] R. J. Bartlett and G. D. Purvis III, Physica Scripta 21, 255 (1980). 
[20] G. E. Scuseria, C. L. Janssen, and H. F. Schaefer III, J. Chem. Phys. 89, 7382 (1988).

[21] G. E. Scuseria and H. F. Schaefer III, J. Chem. Phys. 90, 3700 (1989).

[22] J. A. Pople, M. Head-Gordon, and K. Raghavachari, J. Chem. Phys. 87, 5968 (1987).

[23] T. H. Dunning, J. Chem. Phys. 90, 1007 (1989).

[24] R. A. Kendall, T.H. Dunning Jr., and R. J. Harrison, J. Chem. Phys. 96, 6796 (1992).

[25] D. E. Woon and T. H. Dunning Jr., J. Chem. Phys. 98, 1358 (1993).

[26] K.A. Peterson, D.E. Woon, and T.H. Dunning Jr., J. Chem. Phys. 100, 7410 (1994).

[27] A. K. Wilson, T. van Mourik, and T. H. Dunning Jr., J. Mol. Struct. (Theochem) 388, 339 (1996).

[28] D. G. Truhlar, Chem. Phys. Lett. 45, 45 (1998).

[29] P. L. Fast, M. L. Sánchez, and D. G. Truhlar, J. Chem. Phys. 111, 2921 (1999).

[30] Gaussian 03, Revision D.02, M. J. Frisch, G. W. Trucks, H. B. Schlegel, G. E. Scuseria, M. A. Robb, J. R. Cheeseman, J. A. Montgomery Jr., T. Vreven, K. N. Kudin, J.C. Burant, J. M. Millam, S. S. Iyengar, J. Tomasi, V. Barone, B. Mennucci, M. Cossi, G. Scalmani, N. Rega, G. A. Petersson, H. Nakatsuji, M. Hada, M. Ehara, K. Toyota, R. Fukuda,
J. Hasegawa, M. Ishida, T. Nakajima, Y. Honda, O. Kitao, H. Nakai, M. Klene, X. Li, J.E. Knox, H.P. Hratchian, J. B. Cross, V. Bakken, C. Adamo, J. Jaramillo, R. Gomperts, R. E. Stratmann, O. Yazyev, A. J. Austin, R. Cammi, C. Pomelli, J. W. Ochterski, P. Y. Ayala, K. Morokuma, G. A. Voth, P. Salvador, J. J. Dannenberg, V. G. Zakrzewski, S. Dapprich, A. D. Daniels, M. C. Strain, O. Farkas, D. K. Malick, A. D. Rabuck, K. Raghavachari, J. B. Foresman, J. V. Ortiz, Q. Cui, A. G. Baboul, S. Clifford, J. Cioslowski, B. B. Stefanov, G. Liu, A. Liashenko, P. Piskorz, I. Komaromi, R. L. Martin, D. J. Fox, T. Keith, M. A. AlLaham, C. Y. Peng, A. Nanayakkara, M. Challacombe, P. M. W. Gill, B. Johnson, W. Chen, M.W. Wong, C. Gonzalez, and J. A. Pople, Gaussian, Inc., Wallingford CT, 2004.

[31] W. J. Hehre, R. Ditchfield, L. Radom, and J. A. Pople, J. Am. Chem. Soc. 92, 4796 (1970).

[32] P. Čársky and M. Urban, Ab Initio Calculations. Lecture Notes in Chemistry Vol. 16, SpringerVerlag, Berlin, Heidelberg, New York 1980, p. 75.

[33] W. J. Hehre, L. Radom, P. von R. Schleyer, and J. A. Pople, Ab Initio Molecular Orbital Theory, John Wiley \& Sons Inc., New York 1986, p. 300ff. 